\title{
VERIFICATION SURVEY OF ROOMS 113, 114, AND 208 \\ OF THE INHALATION TOXICOLOGY LABORATORY LOVELACE RESPIRATORY RESEARCH INSTITUTE, ALBUQUERQUE, NEW MEXICO
}

\section{T. J. VITKUS}

\section{Prepared for the}

U.S. Department of Energy

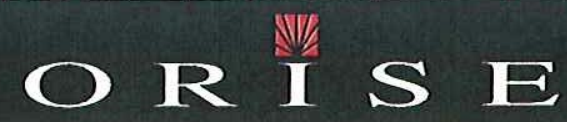

Oak Ridge Institute for Science and Education

Approved for public release; further dissemination unlimited. 
The Oak Ridge Institute for Science and Education (ORISE) is a U.S. Department of Energy facility focusing on scientific initiatives to research health risks from occupational hazards, assess environmental cleanup, respond to radiation medical emergencies, support national security and emergency preparedness, and educate the next generation of scientists. ORISE is managed by Oak Ridge Associated Universities. Established in 1946, ORAU is a consortium of 96 colleges and universities.

\section{NOTICES}

The opinions expressed herein do not necessarily reflect the opinions of the sponsoring institutions of Oak Ridge Associated Universities.

This report was prepared as an account of work sponsored by the United States Government. Neither the United States Government nor the U.S. Department of Energy, nor any of their employees, makes any warranty, expressed or implied, or assumes any legal liability or responsibility for the accuracy, completeness, or usefulness of any information, apparatus, product, or process disclosed, or represents that its use would not infringe on privately owned rights. Reference herein to any specific commercial product, process, or service by trade name, mark, manufacturer, or otherwise, does not necessarily constitute or imply its endorsement or recommendation, or favor by the U.S. Government or any agency thereof. The views and opinions of authors expressed herein do not necessarily state or: reflect those of the U.S. Government or any agency thereof. 


\section{VERIFICATION SURVEY OF \\ ROOMS 113, 114, AND 208 \\ OF THE INHALATION TOXICOLOGY LABORATORY \\ LOVELACE RESPIRATORY RESEARCH INSTITUTE \\ ALBUQUERQUE, NEW MEXICO}

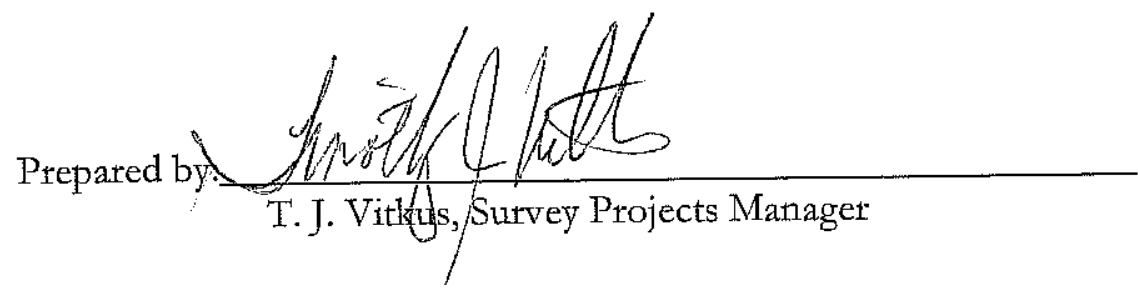

Date: $6 / 23 / 2008$

Reviewed by: Wade \&. prey for

Date: $6 / 24 / 09$

Reviewed by: $\frac{\text { Ann T. Payne, Quality Manager }}{\text { Pare }}$

Date: $6 / 25 / 08$

Reviewed by:

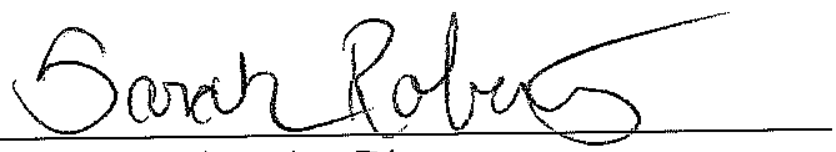

S. J. Roberts, Associate Director

Independent Environmental Assessment and Verification

Date: $6 / 23 / 08$ 


\title{
ACKNOWLEDGMENTS
}

The author would like to acknowledge the significant contributions of the following staff members:

\section{FIELD AND SUPPORT STAFF}

\author{
T.L. Brown
}

\section{LABORATORY STAFF}

R. D. Condra

W. P. Ivey

J. S. Cox

W. F. Smith

\section{CLERICAL STAFF}

R. M. Fink

K. M. Moore

A. Ramsey 


\section{TABLE OF CONTENTS}

PAGE

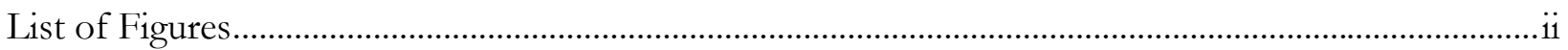

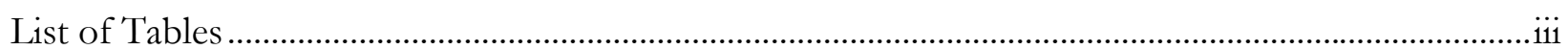

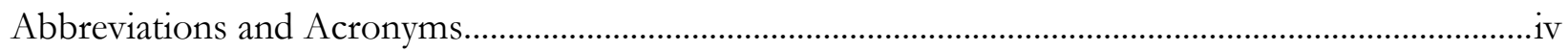

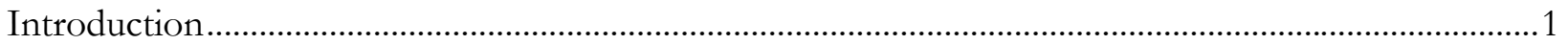

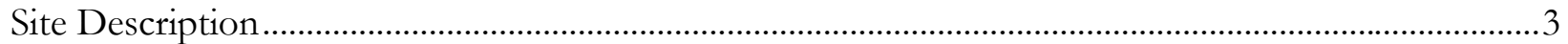

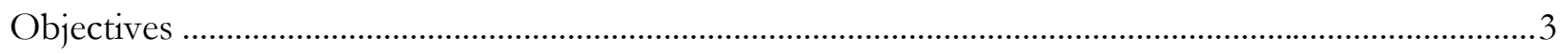

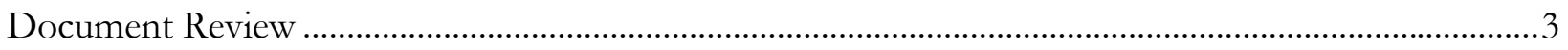

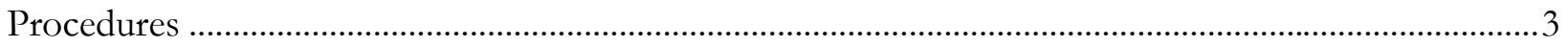

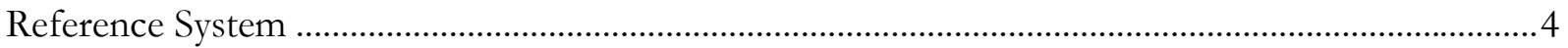

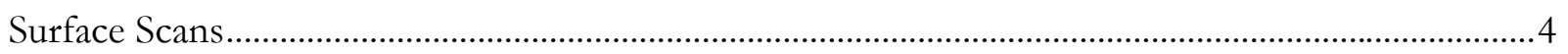

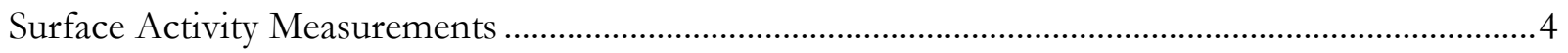

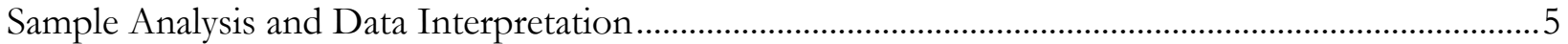

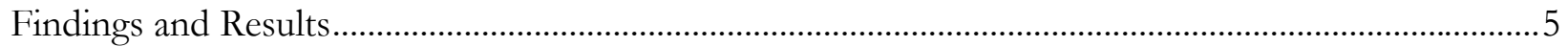

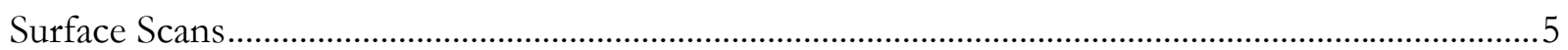

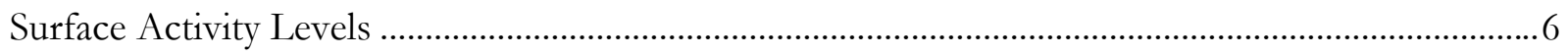

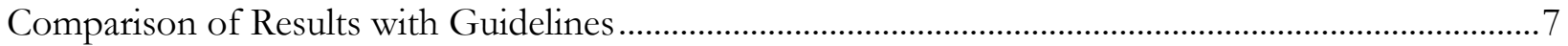

Summary

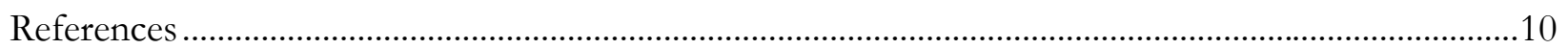

Appendices:

Appendix A Figures

Appendix B Tables

Appendix C Major instrumentation

Appendix D Survey and Analytical Procedures 


\section{LIST OF FIGURES}

Figure A - 1: ITL, Room 113-Measurement and Sampling Locations ............................................ A-1

Figure A - 2: ITL, Room 114-Measurement and Sampling Locations .......................................... A-2

Figure A - 3: ITL, Room 208-Measurement and Sampling Locations ............................................ A-3 


\section{LIST OF TABLES}

Table 1: Prevalent Radionuclides Used at LRRI .....................................................................................

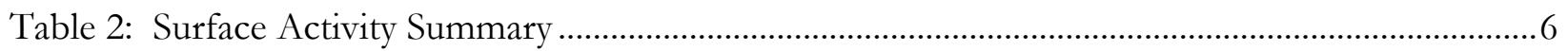

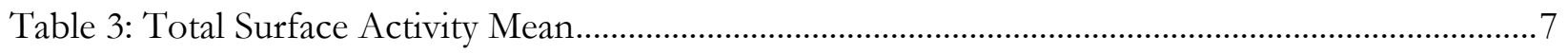

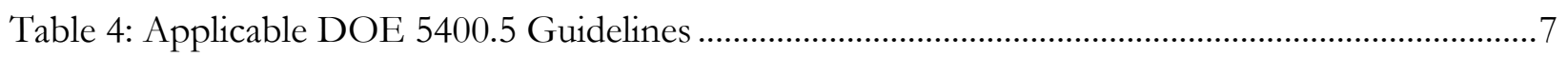

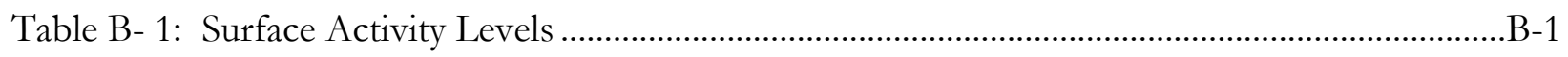

Table B- 2: DOE Residual Contamination Guidelines ........................................................................... 


\section{ABBREVIATIONS AND ACRONYMS}

\begin{tabular}{|c|c|}
\hline$\varepsilon_{\mathrm{i}}$ & instrument efficiency \\
\hline$\varepsilon_{\mathrm{s}}$ & surface efficiency \\
\hline$\varepsilon_{\text {total }}$ & total efficiency \\
\hline$b_{i}$ & background counts in the observation interval \\
\hline $\mathrm{BKG}$ & background \\
\hline $\mathrm{cm}$ & centimeter \\
\hline $\mathrm{cm}^{2}$ & square centimeter \\
\hline cpm & counts per minute \\
\hline DOE & U.S. Department of Energy \\
\hline dpm & disintegrations per minute \\
\hline $\mathrm{dpm} / 100 \mathrm{~cm}^{2}$ & disintegrations per minute per 100 square centimeters \\
\hline EM & Environmental Management \\
\hline IEAV & $\begin{array}{l}\text { Independent Environmental Assessment and Verification } \\
\text { Program }\end{array}$ \\
\hline ISM & Integrated Safety Management \\
\hline ITL & Inhalation Toxicology Laboratory \\
\hline ITP & Intercomparison Testing Program \\
\hline JHA & job hazard analysis \\
\hline LRRI & Lovelace Respiratory Research Institute \\
\hline MAPEP & Mixed Analyte Performance Evaluation Program \\
\hline MDC & minimum detectable concentration \\
\hline MDCR & minimum detectable count rate \\
\hline $\mathrm{MeV}$ & million electron volts \\
\hline $\mathrm{m}$ & meters \\
\hline$m^{2}$ & square meter \\
\hline $\mathrm{mm}$ & millimeter \\
\hline $\mathrm{NaI}$ & sodium iodide \\
\hline NIST & National Institute of Standards and Technology \\
\hline NRC & U.S. Nuclear Regulatory Commission \\
\hline NRIP & NIST Radiochemistry Intercomparison Program \\
\hline ORISE & Oak Ridge Institute for Science and Education \\
\hline ORAU & Oak Ridge Associated Universities \\
\hline
\end{tabular}




\section{VERIFICATION SURVEY OF \\ ROOMS 113, 114, AND 208 \\ OF THE INHALATION TOXICOLOGY LABORATORY \\ LOVELACE RESPIRATORY RESEARCH INSTITUTE \\ ALBUQUERQUE, NEW MEXICO}

\section{INTRODUCTION}

The Inhalation Toxicology Laboratory (ITL) has conducted research for the U.S. Department Energy (DOE) for a number of years. The facility began operations in 1960 as a biomedical research facility under a prime contract to DOE by the Lovelace Respiratory Research Institute (LRRI). The facility changed over to private research in 1996. In conjunction with the changeover to $100 \%$ commercial work, numerous laboratories at the LRRI have been undergoing remedial activities to decontaminate or otherwise address contamination that resulted from DOE-funded research. These decontamination activities have been taking place over the past ten years as part of the DOE's Environmental Management (EM) project.

The LRRI has prepared a transition plan that discusses the radionuclides used in their research and provides a cross reference of radionuclide usage within individual laboratories at the LRRI (LRRI 2008a). Table 1 lists the radionuclides that have been used.

\begin{tabular}{|l|l|l|l||}
\hline \multicolumn{5}{|c|}{ TABLE 1: } \\
\hline PR-3 & Kr-85 & Ce-137 & U-235 \\
\hline C-14 & Sr-90 & Ce-144 & U-236 \\
\hline P-32 & Tc-99 & Ir-192 & U-238 \\
\hline S-35 & Tc-99m & Po-210 & Pu-238 \\
\hline Cr-51 & Ag-110m & Rn-222 & Pu-239 \\
\hline Co-60 & I-125 & Ra-226 & Am-241 \\
\hline Ni-63 & I-131 & Th-232 & Cm-244 \\
\hline
\end{tabular}

Highlighted radionuclide half-lives are less than one year

A number of the listed isotopes have short half-lives ranging from hours to less than one year.

Therefore, dependent upon the time elapsed since their use, these short-lived radionuclides may or may not contribute to any contamination currently present on surfaces. Multiple radionuclides may 
have been used within a given laboratory. However, LRRI has indicated in their transition plan that laboratories were decontaminated prior to beginning the next study (LRRI 2008a).

In conjunction with the changeover of the ITL to commercial work, DOE requested that LRRI submit the aforementioned transition plan for DOE's review and approval. The LRRI transition plan cover letter states that residual contamination may remain from prior research activities, yet LRRI will assume liability and incorporate residual contamination within their NRC license that the commercial work will be operated under. The most notable residual contamination is that which remains in sewer lines and ductwork.

The ITL has committed to evaluating the radiological conditions of those laboratories impacted by DOE-funded research with the DOE's authorized release limits. Contamination identified may be remediated or documented and left in place for incorporation into the NRC license. DOE is responsible for oversight of survey and/or remedial actions that are conducted as a result of DOE-funded missions. It is the policy of DOE to perform independent (third party) verification of the final radiological status of DOE-impacted facilities. The purpose of these independent verification activities is to confirm that remedial actions have been effective in eliminating residual contamination to levels less than the established guidelines or otherwise satisfy the intended property end use for those cases where the property will not be released for unrestricted use. Per the transition plan, the ITL is not intended to be released without radiological restriction. Instead the facility will continue research involving radioactive materials and as such will operate under an NRC license that is to include residual contamination remaining in inaccessible areas, ducts, and drains. The Independent Environmental Assessment and Verification Program (IEAV) of the Oak Ridge Institute for Science and Education (ORISE) was designated as the organization responsible for verifying the radiological status of three ITL laboratories. The laboratories are designated Rooms 113, 114, and 208. The ORISE project statement of work did not include a task for the evaluation of LRRI's survey procedures and plans (Type A verification review). Therefore, this report does not include an independent evaluation of the adequacy of the site's documentation as to the facility's radiological status. 


\section{SITE DESCRIPTION}

The ITL is located on the southern edge of the Kirtland Airforce Base in Albuquerque, New Mexico. The facility was constructed in multiple phases and currently consists of 22,000 square meters $(240,000$ square feet) of laboratory and office space.

Rooms 113, 114, and 208 are small laboratories. Room 113 is 37 square meters and Rooms 114 and 208 are 24 square meters each. Construction consists of concrete floors with tile overlays (Rooms 113 and 114 only) and painted gypsum board or cinder block walls. Radionuclides used included H-3 and C-14 in Rooms 113 and 114; and Sr-90, Cs-134, H-3, C-14, and Cs-137 (sealed sources only) in Room 208 (LRRI 2008b).

\section{OBJECTIVES}

The objectives of the verification survey were to confirm that accessible surfaces of the three laboratories meet the DOE's established criteria for residual contamination. Drain pipes and ductwork were not included within the survey scope.

\section{DOCUMENT REVIEW}

ORISE reviewed the Transition Plan to determine the radionuclide use history for the ITL (LRRI 2008a). Additionally, the LRRI survey data for the laboratories were reviewed to determine the current residual activity levels and to assist in determining the number of verification measurements.

\section{PROCEDURES}

ORISE personnel visited the ITL site to perform visual inspections and independent measurements and sampling. The verification activities were conducted in accordance with a site-specific survey plan, the ORISE Survey Procedures Manual and the ORAU Quality Program Manual (ORISE 2008a and b and ORAU 2007). 
The tasks consisted of verification surveys of three laboratories. ITL had established two categories for rooms within the facility, Categories A and B. Category A rooms did not have a history of radioactive material use and Category B rooms were rooms that had been used or potentially used for studies involving radioactive materials. Rooms 113, 114, and 208 were designated as Category B.

\section{REFERENCE SYSTEM}

Scaled drawings were prepared for each room using Visual Sample Plan v.4.6. Floor measurement and sampling locations were referenced as $\mathrm{X}, \mathrm{Y}$ coordinates to the lower left room corner as viewed from the doorway. Lower wall locations included a $\mathrm{Z}$ coordinate for the height above the floor.

\section{SURFACE SCANS}

High density surface scans for alpha, alpha plus beta, and gamma radiation were conducted over accessible floor surfaces; and medium density scans were performed on the lower wall (up to 2 meters) surfaces. Upper wall and ceilings were not scanned due to scope of work constraints and low potential for having become contaminated. Surface scans were performed using gas proportional and $\mathrm{NaI}$ scintillation detectors coupled to ratemeters or ratemeter-scalers with audible indicators. Locations of elevated direct radiation, suggesting the presence of residual contamination, were marked and identified for judgmental measurements. Inaccessible surfaces such as drains and ductwork were not included within the scope of the verification, although the floor drain openings were scanned with the floors.

\section{SURFACE ACTIVITY MEASUREMENTS}

Static direct measurements were made to quantify total alpha and total beta activity levels. Construction material-specific background measurements were determined within hallways that were similarly constructed. Direct measurements were performed at 10 to 11 random locations per room using gas proportional detectors coupled to ratemeter-scalers. Figures A-1 through A-3 show each room and the random measurement locations. These measurements, after correcting for material-specific backgrounds, were used to estimate each room's mean residual activity level. There 
were three locations of elevated beta radiation detected in Room 208-discussed further in the Findings and Results section below-that also required direct measurements. One of these areas had been pre-planned for a random measurement. The other two identified areas required judgmental measurements which were collected at both remaining locations of elevated direct radiation shown on Figure A-3. Dual smear samples, one dry smear and one wet smear, were collected from each random and judgmental measurement location to quantify removable gross alpha, gross beta, H-3, and C-14 activity.

\section{SAMPLE ANALYSIS AND DATA INTERPRETATION}

Samples and data were returned to the ORISE/IEAV laboratory in Oak Ridge, Tennessee for analysis and interpretation. Sample analyses were performed in accordance with the ORISE/IEAV Laboratory Procedures Manual (ORISE 2008c). Dry smears were analyzed using a low-background proportional counter. Wet smears were analyzed by liquid scintillation counting for H-3 and C-14.

Smear data and direct measurement data were converted to units of disintegrations per minute per $100 \mathrm{~cm}^{2}\left(\mathrm{dpm} / 100 \mathrm{~cm}^{2}\right)$. The data generated were compared with the DOE Order 5400.5 guidelines and supplemental guidance specified in the transition plan (DOE 1993 and 1995).

\section{FINDINGS AND RESULTS}

The results for the verification survey are provided below. Additional information regarding instrumentation and procedures may be found in Appendices C and D.

\section{SURFACE SCANS}

Gamma radiation surface scans did not identify any radiation levels in excess of the ambient backgrounds. The gamma scans ranged from 4,500 to 6,000 counts per minute (cpm) for floors and lower walls with a nominal background of 4,500 to 5,000 cpm. Alpha scans also did not identify any

alpha radiation above background with scans ranging from 0 to $20 \mathrm{cpm}$ for floors and lower walls. Alpha plus beta scans did not identify any elevated direct radiation in Rooms 113 and 114. Floor 
scans ranged from 1,300 to 2,700 cpm using the large-area floor monitor and from 250 to $550 \mathrm{cpm}$ for lower walls in Rooms 113 and 118. In room 208, most of the lower wall scan ranges were similar to the other rooms with the exception of three areas of elevated direct radiation identified on the west wall that ranged from 2,000 to 9,000 cpm.

\section{SURFACE ACTIVITY LEVELS}

The results for individual total and removable surface activity assessments are provided in Table B-1. Table 2 below provides a summary of the results for each of the rooms surveyed and Table 3 reports the mean total surface activity level for each room. The surface activity results presented in Tables B-1, 2, and 3 are net activity levels that have been corrected for instrument/detector, ambient, and construction material background contributions. Because background counts are random events characterized by a Gaussian distribution, reported net surface activity levels collected from a background population will exhibit the same distribution and be centered around a mean of zero, with both positive and negative tails. Additionally, a small sample size $(n<30)$ can result in a positive or negative bias of the sample mean as seen in the results for Rooms 113 and 114 in Table 3.

\begin{tabular}{|c|c|c|c|c|c|c|}
\hline \multicolumn{7}{|c|}{$\begin{array}{c}\text { TABLE 2: } \\
\text { SURFACE ACTIVITY SUMMARY }\end{array}$} \\
\hline \multirow{2}{*}{ Room } & \multicolumn{2}{|c|}{$\begin{array}{c}\text { Total Activity Range } \\
\left(\mathbf{d p m} / \mathbf{1 0 0} \mathbf{~ c m}^{\mathbf{2}}\right)\end{array}$} & \multicolumn{5}{c|}{$\begin{array}{c}\text { Removable Activity Range } \\
\left(\mathbf{d p m} / \mathbf{1 0 0} \mathbf{~ c m}^{2}\right)\end{array}$} \\
\cline { 2 - 7 } & Alpha & Beta & Alpha & Beta & H-3 & C-14 \\
\hline \hline $\mathbf{1 1 3}$ & -18 to 9 & -160 to -44 & 0 to 3 & -5 to 5 & -9 to -1 & -4 to 2 \\
\hline $\mathbf{1 1 4}$ & -26 to 0 & -130 to 120 & 0 to 1 & -4 to 4 & -8 to 37 & -1 to 4 \\
\hline $\mathbf{2 0 8}$ & -35 to 26 & -41 to 24,000 & 0 to 3 & -4 to 19 & -10 to 16 & -1 to 8 \\
\hline
\end{tabular}

Table 2 includes the results for all measurements, both random and judgmental. The mean total surface activity levels are provided in Table 3. These reported mean activities are the arithmetic averages of the random measurement sample population and do not include judgmental measurements. 


\begin{tabular}{|c|c|c||}
\hline \multicolumn{3}{|c|}{ TATAL SURFACE ACTIVITY MEAN } \\
\hline \multirow{2}{*}{ Room } & \multicolumn{2}{|c|}{ Mean $\left(\mathrm{dpm} / 100 \mathrm{~cm}^{2}\right)$} \\
\cline { 2 - 4 } & Alpha & Beta \\
\hline \hline 113 & -10 & -110 \\
\hline 114 & -10 & -45 \\
\hline 208 & -1 & 1,200 \\
\hline
\end{tabular}

Note: Random measurement location \#30 in Room 208 fell within one of the three locations of elevated direct beta radiation identified.

\section{COMPARISON OF RESULTS WITH GUIDELINES}

Surface activity levels were compared with the DOE Order 5400.5 guidelines (DOE 1993 and 1995). These guidelines, presented in Table B-2, have five categories of allowable residual contamination levels that are based on radionuclide groupings. Additionally, these guidelines are further subdivided into average activity levels allowed per $1 \mathrm{~m}^{2}$, maximum activity within a $100 \mathrm{~cm}^{2}$ area, and removable activity. Because historical research had included the use of radionuclides in each of the categories, the most restrictive guidelines were selected for comparing data. The guidelines selected for alpha were those for transuranics and the guidelines for beta were those for Sr-90. H-3 has a single removable activity guideline. Table 4 lists these guidelines.

\begin{tabular}{|c|c|c|c|}
\hline \multicolumn{4}{|c|}{ TABLE 4: } \\
APPLICABLE DOE 5400.5 GUIDELINES \\
\hline Category & $\begin{array}{c}\text { Average Activity } \\
\text { (averaged over a 1 m area) }\end{array}$ & $\begin{array}{c}\text { Maximum Activity } \\
\text { (maximum in a 100 cm area) }\end{array}$ & Removable Activity \\
\hline \hline Transuranics & $100 \alpha \mathrm{dpm} / 100 \mathrm{~cm}^{2}$ & $300 \alpha \mathrm{dpm} / 100 \mathrm{~cm}^{2}$ & $20 \alpha \mathrm{dpm} / 100 \mathrm{~cm}^{2}$ \\
\hline Sr-90 & $1,000 \mathrm{dpm} / 100 \mathrm{~cm}^{2}$ & $3,000 \mathrm{dpm} / 100 \mathrm{~cm}^{2}$ & $200 \mathrm{dpm} / 100 \mathrm{~cm}^{2}$ \\
\hline H-3 & NA & NA & $10,000 \mathrm{dpm} / 100 \mathrm{~cm}^{2}$ \\
\hline
\end{tabular}


Selection of the most restrictive guidelines for beta-emitters also included considerations for other contaminants that may have been present such as C-14 which is in a different guideline category. This is further discussed in Appendix D.

The evaluation of the surface activity data combined with the results of surface scans showed that the surface activity levels in Rooms 113 and 114 were indistinguishable from background and therefore satisfy both the average and maximum surface activity guidelines. That is, individual results do not exceed the maximum allowable levels and the Table 3 mean values represent activity levels that may be present in any given $1 \mathrm{~m}^{2}$ area. Room 208, however, has residual beta contamination in excess of the maximum allowable guideline levels. The contamination identified was localized on the west wall over a 1 to $2 \mathrm{~m}^{2}$ area. Typically when a site performs final surveys for unrestricted release, the site must demonstrate compliance with both the average and maximum total activity 5400.5 guidelines. This has historically involved performing direct measurements every 1 to $4 \mathrm{~m}^{2}$, dependent upon scan sensitivities. Verification surveys ensured that neither guideline was exceeded primarily via surface scanning to identify locations of elevated direct radiation. Judgmental verification measurements would then be made. If activity levels were between the average and maximum guideline, and the affected area was less than $1 \mathrm{~m}^{2}$ in size, then additional measurements would be made to determine the average activity level and whether or not the average guideline was met. However, for the ITL, the site is not being released and the site's surveys were not performed in a manner that would demonstrate compliance in accordance with prior final status survey guidance documents such as draft NUREG/CR-5849. As such, the verification survey was designed to identify residual hot spots and to provide an estimate of the overall mean activity level using the site's data as input parameters. Because of the hot spots present in Room 208, the small sample size, and the resultant large standard deviation of the measurement results, the calculated mean activity concentration shown for Room 208 is most likely skewed. A more precise estimate of the mean would require a larger sample size. The median beta activity was $51 \mathrm{dpm} / 100 \mathrm{~cm}^{2}$ and may better represent what the average activity level would be if a larger sample population size were collected or following remediation of the residual contamination.

Alternatively, the weighted average could be estimated but would require substantiation. An estimated weighted average would be based on the total floor and lower wall (up to $2 \mathrm{~m}^{2}$ ) area of 
$49 \mathrm{~m}^{2}$. The average activity for the contaminated $2 \mathrm{~m}^{2}$ west wall area is $14,000 \mathrm{dpm} / 100 \mathrm{~cm}^{2}$ and the average activity for the remaining $47 \mathrm{~m}^{2}$ is $47 \mathrm{dpm} / 100 \mathrm{~cm}^{2}$ (excludes measurement locations 30, 33, and 34). The weighted average is therefore:

$\left(47 \mathrm{~m}^{2} / 49 \mathrm{~m}^{2}\right)\left(47 \mathrm{dpm} / 100 \mathrm{~cm}^{2}\right)+\left(2 \mathrm{~m}^{2} / 49 \mathrm{~m}^{2}\right)\left(14,000 \mathrm{dpm} / 100 \mathrm{~cm}^{2}\right)=610 \mathrm{dpm} / 100 \mathrm{~cm}^{2}$.

Therefore, it is ORISE's opinion that if the locations exceeding the maximum guideline were to be remediated then the average activity level guideline would be met in Room 208. All removable activity levels were less than the guidelines.

\section{SUMMARY}

ORISE personnel performed a verification survey of three former laboratories at the Inhalation Toxicology Laboratory in Albuquerque, New Mexico on May 29, 2008. The verification surveys included surface scans for gamma, alpha, and alpha plus beta radiation; direct measurements for alpha and beta surface activity levels; and smear sampling to determine removable levels for gross alpha, gross beta, H-3, and C-14. The survey identified residual contamination exceeding the DOE guidelines in Room 208. There was no residual contamination identified on the floors or lower walls of Rooms 113 and 114. 


\section{REFERENCES}

Lovelace Respiratory Research Institute (LLRI). Radiological Release Transition Plan. Albuquerque, NM: April 10, 2008a.

Lovelace Respiratory Research Institute. Personal communication from E. Marshall. May 28, 2008b.

Oak Ridge Associated Universities (ORAU). Quality Program Manual for the Independent Environmental Assessment and Verification Program. Oak Ridge, TN; November 1, 2007.

Oak Ridge Institute for Science and Education (ORISE). Verification Survey Plan for Rooms 113, 114, and 208 of the Inhalation Toxicology Laboratory, Lovelace Respiratory Institute, Albuquerque, New Mexico (DCN 0491-PL-01-0. Oak Ridge, TN; May 27, 2008a.

Oak Ridge Institute for Science and Education. Survey Procedures Manual for the Independent Environmental Assessment and Verification Program. Oak Ridge, TN; May 1, 2008b.

Oak Ridge Institute for Science and Education. Laboratory Procedures Manual for the Independent Environmental Assessment and Verification Program. Oak Ridge, TN; March 3, 2008c.

U.S. Department of Energy (DOE). Radiation Protection of the Public and the Environment. Washington, DC: DOE Order 5400.5; January 7, 1993.

U.S. Department of Energy. Memorandum from R. Pelletier to Distribution, "Application of DOE 5400.5 Requirements for Release and Control of Property Containing Residual Radioactive Material"; November 17, 1995. 
APPENDIX A

\section{FIGURES}




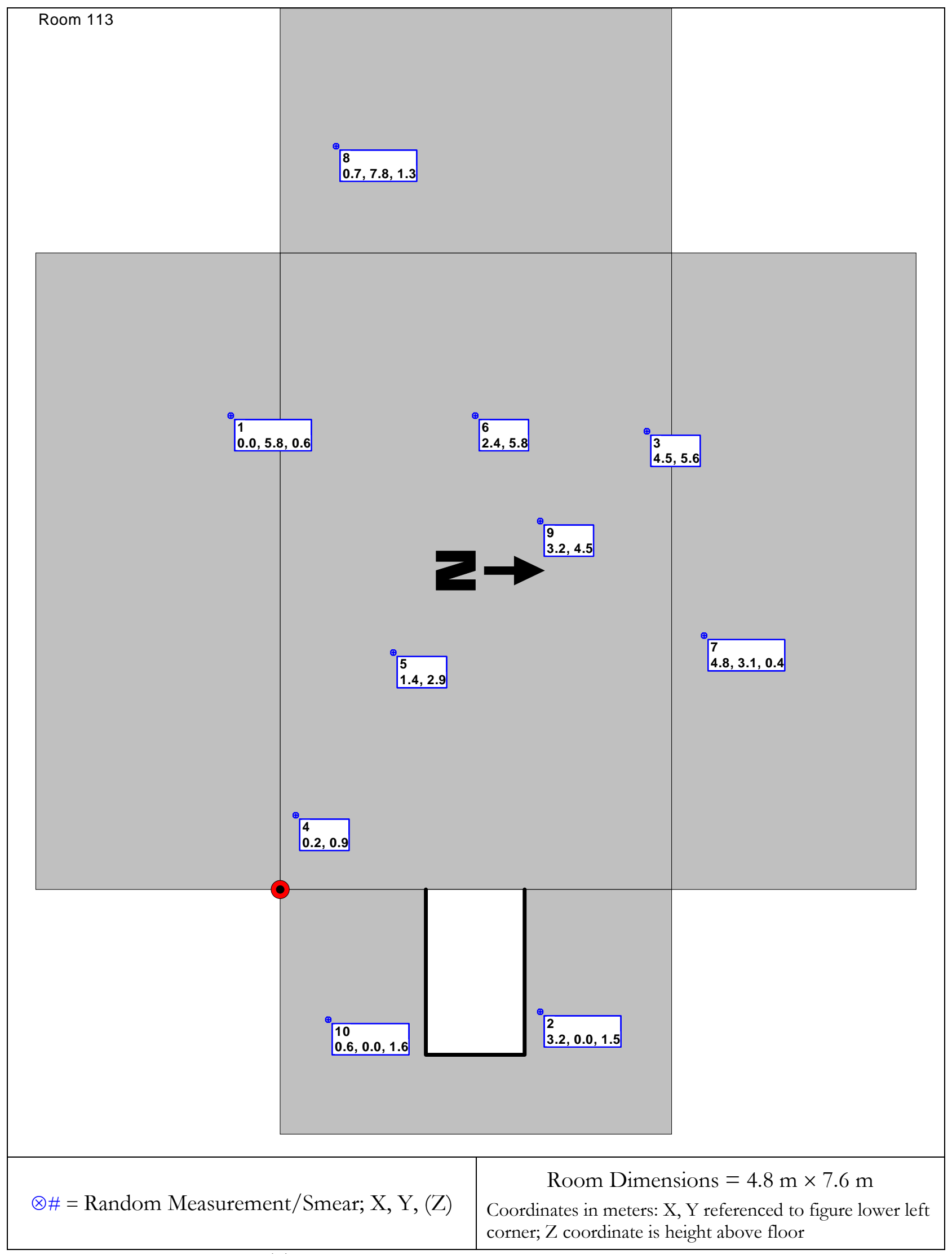

Figure A - 1: ITL, Room 113-Measurement and Sampling Locations 


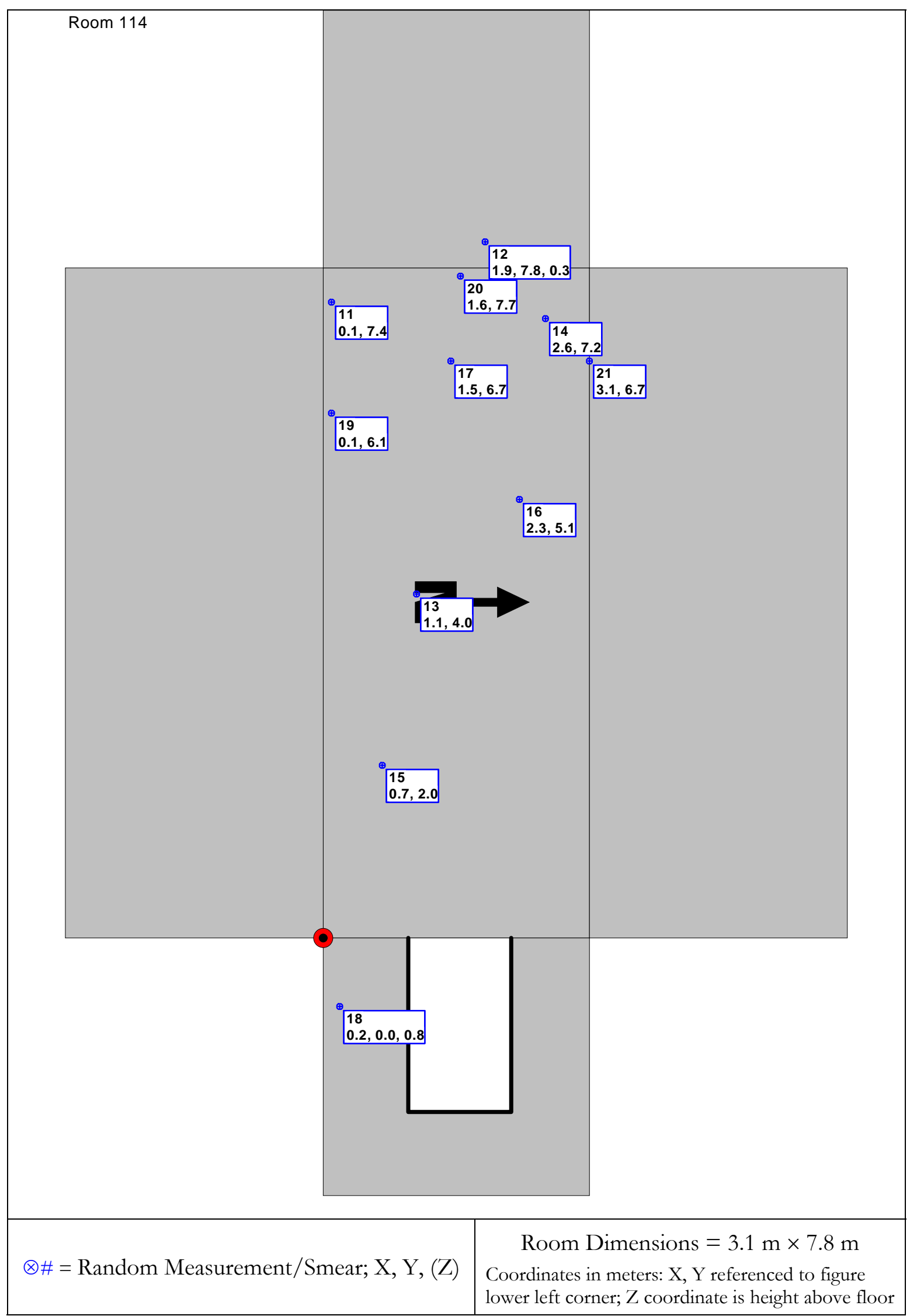

Figure A - 2: ITL, Room 114-Measurement and Sampling Locations 


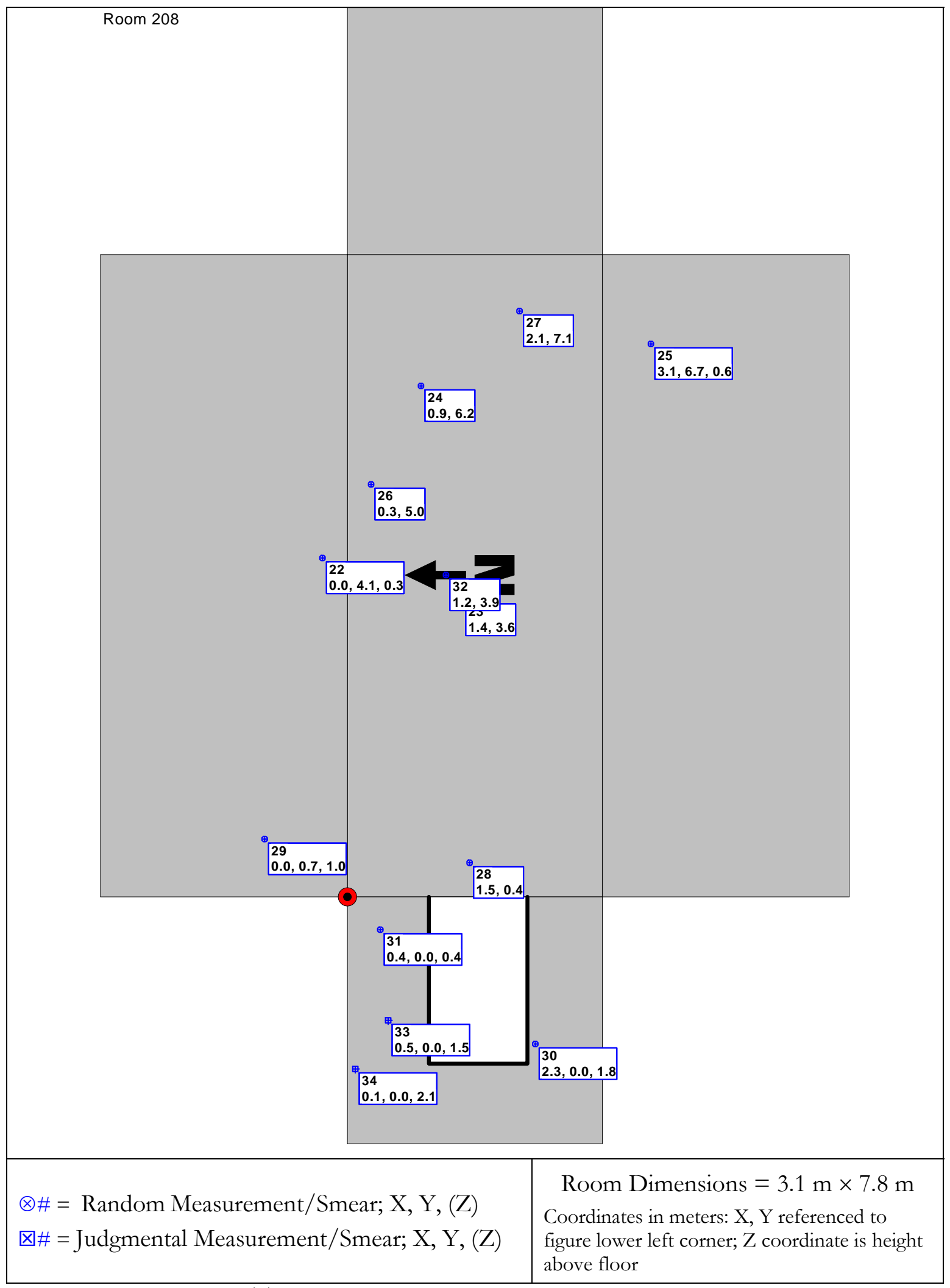

Figure A - 3: ITL, Room 208-Measurement and Sampling Locations 
APPENDIX B

TABLES 


\begin{tabular}{|c|c|c|c|c|c|c|}
\hline & INF & $\begin{array}{l}\text { URFA } \\
\text { ION } \\
\text { 3UQL }\end{array}$ & $\begin{array}{l}\text { 3LE B- } \\
\text { CTIVIT } \\
\text { COLO } \\
\text { UE, NE }\end{array}$ & $\begin{array}{l}\text { EVEL } \\
\text { ABO } \\
\text { MEXIC }\end{array}$ & & \\
\hline Room\#/ & $\begin{array}{r}\text { To } \\
\text { (dpr }\end{array}$ & $\begin{array}{l}\text { ivity } \\
\left.\mathrm{cm}^{2}\right)^{\mathrm{b}}\end{array}$ & & $\begin{array}{r}\text { Rem } \\
\text { (dp }\end{array}$ & $\begin{array}{l}\text { Activi } \\
\left.\mathbf{c m}^{2}\right)^{1}\end{array}$ & \\
\hline & Alpha & Beta & Alpha & Beta & H-3 & C-14 \\
\hline $\mathrm{Rm}$ 113/1 & -9 & -92 & 0 & -1 & -9 & 0 \\
\hline $\mathrm{Rm} \mathrm{113/2}$ & 9 & -110 & 1 & 2 & -5 & -1 \\
\hline $\mathrm{Rm} \mathrm{113/3}$ & -18 & -130 & 0 & -3 & -2 & -1 \\
\hline $\mathrm{Rm} 113 / 4$ & -9 & -140 & 0 & 5 & -2 & 2 \\
\hline $\mathrm{Rm} 113 / 5$ & -18 & -100 & 3 & -4 & -5 & 2 \\
\hline $\mathrm{Rm} 113 / 6$ & -9 & -100 & 0 & -1 & -1 & -1 \\
\hline $\mathrm{Rm} 113 / 7$ & -9 & -100 & 0 & -5 & -2 & 1 \\
\hline $\mathrm{Rm} 113 / 8$ & -9 & -84 & 0 & -5 & -2 & -4 \\
\hline $\mathrm{Rm} \mathrm{113/9}$ & -18 & -44 & 0 & -3 & -7 & 1 \\
\hline $\mathrm{Rm} 113 / 10$ & -9 & -160 & 1 & -2 & -6 & 1 \\
\hline $\mathrm{Rm} 114 / 11$ & -9 & -61 & 0 & -3 & -2 & 1 \\
\hline $\mathrm{Rm} 114 / 12$ & -9 & 120 & 1 & 1 & -7 & -1 \\
\hline Rm 114/13 & -26 & -28 & 0 & -2 & -8 & 3 \\
\hline Rm 114/14 & -18 & -130 & 1 & -2 & 19 & 1 \\
\hline Rm 114/15 & -9 & -44 & 0 & -3 & -8 & 3 \\
\hline Rm 114/16 & 0 & -59 & 0 & -2 & 6 & 0 \\
\hline $\mathrm{Rm} 114 / 17$ & -18 & -110 & 0 & 3 & 37 & 4 \\
\hline $\mathrm{Rm} 114 / 18$ & 0 & 20 & 0 & -4 & -3 & 4 \\
\hline $\mathrm{Rm} 114 / 19$ & 0 & -95 & 0 & 4 & -4 & 0 \\
\hline $\mathrm{Rm} 114 / 20$ & -26 & -130 & 0 & -3 & 0 & 2 \\
\hline $\mathrm{Rm} 114 / 21$ & 0 & 20 & 0 & 2 & -4 & 0 \\
\hline $\mathrm{Rm} 208 / 22$ & -9 & 160 & 1 & -4 & -2 & 7 \\
\hline Rm 208/23 & -18 & 82 & 0 & -4 & -2 & -1 \\
\hline $\operatorname{Rm} 208 / 24$ & 18 & 51 & 1 & 1 & -8 & -1 \\
\hline $\operatorname{Rm} 208 / 25$ & 0 & -41 & 0 & 19 & 1 & 2 \\
\hline $\operatorname{Rm} 208 / 26$ & 0 & 90 & 0 & -2 & -2 & -1 \\
\hline $\operatorname{Rm} 208 / 27$ & 0 & -23 & 0 & -2 & 8 & -1 \\
\hline $\mathrm{Rm} 208 / 28$ & -35 & 44 & 3 & 3 & 16 & 6 \\
\hline
\end{tabular}




\begin{tabular}{|c|c|c|c|c|c|c|}
\hline \multirow{3}{*}{$\begin{array}{l}\text { Room\#/ } \\
\text { Location }^{\text {a }}\end{array}$} & \multicolumn{5}{|c|}{$\begin{array}{c}\text { TABLE B-1: } \\
\text { SURFACE ACTIVITY LEVELS } \\
\text { INHALATION TOXICOLOGY LABORATORY } \\
\text { ALBUQUERQUE, NEW MEXICO }\end{array}$} & \\
\hline & \multicolumn{2}{|c|}{$\begin{array}{l}\text { Total Activity } \\
\left(\mathrm{dpm} / 100 \mathrm{~cm}^{2}\right)^{\mathrm{b}}\end{array}$} & \multicolumn{4}{|c|}{$\begin{array}{l}\text { Removable Activity } \\
\left(\mathrm{dpm} / 100 \mathrm{~cm}^{2}\right)^{\mathrm{b}}\end{array}$} \\
\hline & Alpha & Beta & Alpha & Beta & H-3 & C-14 \\
\hline Rm 208/29 & 0 & 51 & 0 & 8 & 1 & 3 \\
\hline $\operatorname{Rm} 208 / 30$ & 9 & 13,000 & 0 & 4 & 4 & 8 \\
\hline Rm 208/31 & 26 & -26 & 0 & 1 & -2 & 2 \\
\hline $\operatorname{Rm} 208 / 32$ & -9 & 41 & 0 & -4 & 1 & 1 \\
\hline Rm 208/33 & 0 & 4,200 & 0 & -1 & -10 & 3 \\
\hline $\operatorname{Rm} 208 / 34$ & 0 & 24,000 & 0 & -3 & -1 & 3 \\
\hline
\end{tabular}

${ }^{a}$ Refer to Figures A-1 through A-3

bActivities are reported as net activities after correcting for background contributions. 


\begin{tabular}{|c|c|c|c|}
\hline \multicolumn{4}{|c|}{$\begin{array}{c}\text { TABLE B- } 2: \\
\text { DOE RESIDUAL CONTAMINATION GUIDELINES }\end{array}$} \\
\hline Radionuclide $^{\mathrm{b}}$ & $\begin{array}{l}\text { Average Activity } \\
\left(\mathrm{dpm} / 100 \mathrm{~cm}^{2}\right)^{\mathrm{a}, \mathrm{c}, \mathrm{d}}\end{array}$ & $\begin{array}{l}\text { Maximum Activity } \\
\left(\mathrm{dpm} / 100 \mathrm{~cm}^{2}\right)^{\mathrm{a}, \mathrm{d}, \mathrm{e}}\end{array}$ & $\begin{array}{l}\text { Removable Activity } \\
\left(\mathrm{dpm} / 100 \mathrm{~cm}^{2}\right)^{\mathrm{a}, \mathrm{f}}\end{array}$ \\
\hline $\begin{array}{l}\text { U-nat, U-235, U-238, } \\
\text { and associated decay } \\
\text { products }\end{array}$ & $5,000 \propto \mathrm{dpm} 100 \mathrm{~cm}^{2}$ & $15,000 \propto \mathrm{dpm} 100 \mathrm{~cm}^{2}$ & $1,000 \propto \mathrm{dpm} 100 \mathrm{~cm}^{2}$ \\
\hline $\begin{array}{l}\text { Transuranics, Ra-226, } \\
\text { Ra-228, Th-230, Th-228, } \\
\text { Pa-231, Ac-227, I-125, } \\
\text { I-129 }\end{array}$ & $100 \mathrm{dpm} 100 \mathrm{~cm}^{2}$ & $300 \mathrm{dpm} 100 \mathrm{~cm}^{2}$ & $20 \mathrm{dpm} 100 \mathrm{~cm}^{2}$ \\
\hline $\begin{array}{l}\text { Th-nat, Th-232, Sr-90, } \\
\text { Ra-223, Ra-224, U-232, } \\
\text { I-126, I-131, I-133 }\end{array}$ & $1,000 \mathrm{dpm} 100 \mathrm{~cm}^{2}$ & $3,000 \mathrm{dpm} 100 \mathrm{~cm}^{2}$ & $200 \mathrm{dpm} 100 \mathrm{~cm}^{2}$ \\
\hline $\begin{array}{l}\text { H-3 and tritiated } \\
\text { compounds }\end{array}$ & NA & NA & $10,000 \mathrm{dpm} 100 \mathrm{~cm}^{2}$ \\
\hline $\begin{array}{l}\text { Beta-gamma emitters } \\
\text { (nulcides with decay } \\
\text { modes other than alpha } \\
\text { emission or } \\
\text { spontaneous fission) } \\
\text { except Sr-90 and others } \\
\text { noted above }\end{array}$ & $5,000 \beta \gamma$ dpm $100 \mathrm{~cm}^{2}$ & $15,000 \beta \gamma \mathrm{dpm} 100 \mathrm{~cm}^{2}$ & $1,000 \beta \gamma \mathrm{dpm} 100 \mathrm{~cm}^{2}$ \\
\hline
\end{tabular}

a As used in this table, dpm (disintegrations per minute) means the rate of emission by radioactive material as determined by correcting the counts per minute measured by an appropriate detector for background, efficiency, and geometric factors associated with the instrumentation.

b Where surface contamination by both alpha- and beta-gamma-emitting radionuclides exists, the limits established for alpha- and beta-gamma-emitting radionuclides should apply independently.

c Measurements of average contamination should not be averaged over an area of more than $1 \mathrm{~m}^{2}$. For objects of less surface area, the average should be derived for each such object.

$\mathrm{d}$ The average and maximum dose rates associated with surface contamination resulting from beta-gamma emitters should not exceed $0.2 \mathrm{mrad} / \mathrm{h}$ and $1.0 \mathrm{mrad} / \mathrm{h}$, respectively, at a depth of $1 \mathrm{~cm}$.

e The maximum contamination level applies to an area of not more than $100 \mathrm{~cm}^{2}$.

${ }^{\mathrm{f}}$ The amount of removable radioactive material per $100 \mathrm{~cm}^{2}$ of surface area should be determined by wiping an area of that size with dry filter or soft absorbent paper, applying moderate pressure, and measuring the amount of radioactive material on the wipe with an appropriate instrument of known efficiency. When removable contamination on objects of surface area less than $100 \mathrm{~cm}^{2}$ is determined, the activity per unit area should be based on the actual area and the entire surface should be wiped. The numbers in this column are maximum amounts.

$\mathrm{g}$ This category of radionuclides includes mixed fission products, including the Sr-90 which has been separated from the other fission products or mixtures where the Sr-90 has been enriched. 
APPENDIX C

\section{MAJOR INSTRUMENTATION}




\title{
APPENDIX C
}

\section{MAJOR INSTRUMENTATION}

The display of a specific product is not to be construed as an endorsement of the product or its manufacturer by the author or his employer.

\section{SCANNING INSTRUMENT/DETECTOR COMBINATIONS}

\author{
Alpha \\ Ludlum Floor Monitor Model 239-1 \\ combined with \\ Ludlum Ratemeter-Scaler Model 2221 \\ coupled to \\ Ludlum Gas Proportional Detector Model 43-37, Physical Area: $550 \mathrm{~cm}^{2}$ \\ (Ludlum Measurements, Inc., Sweetwater, TX)
}

\section{Alpha plus Beta}

Ludlum Floor Monitor Model 239-1

combined with

Ludlum Ratemeter-Scaler Model 2221

coupled to

Ludlum Gas Proportional Detector Model 43-37, Physical Area: $550 \mathrm{~cm}^{2}$

(Ludlum Measurements, Inc., Sweetwater, TX)

\section{Alpha and Beta}

Ludlum Ratemeter-Scaler Model 2221

coupled to

Ludlum Gas Proportional Detector Model 43-68, Physical Area: $126 \mathrm{~cm}^{2}$

(Ludlum Measurements, Inc., Sweetwater, TX)

\section{Gamma}

Ludlum Pulse Ratemeter Model 12

(Ludlum Measurements, Inc., Sweetwater, TX)

coupled to

Fluke Miomedical NaI Scintillation Detector Model 489-55, Crystal: $3.2 \mathrm{~cm}$ x $3.8 \mathrm{~cm}$

(Fluke Biomedical, Cleveland, $\mathrm{OH}$ ) 


\section{Direct Measurement InSTRUment/Detector Combinations}

\section{Alpha and Beta}

Ludlum Ratemeter-Scaler Model 2221

coupled to

Ludlum Gas Proportional Detector Model 43-68, Physical Area: $126 \mathrm{~cm}^{2}$

(Ludlum Measurements, Inc., Sweetwater, TX)

\section{LABORATORY ANALYTICAL INSTRUMENTATION}

Low Background Gas Proportional Counter

Model LB-5100-W

(Tennelec/Canberra, Meriden, CT)

Tri-Carb Liquid Scintillation Analyzer

Model 3100

(Packard Instrument Co., Meriden, CT) 
APPENDIX D

SURVEY AND ANALYTICAL PROCEDURES 


\section{APPENDIX D \\ SURVEY AND ANALYTICAL PROCEDURES}

\section{Project Health AND SAFETy}

The proposed survey and sampling procedures were evaluated to ensure that any hazards inherent to the procedures themselves were addressed in current job hazard analyses (JHAs). All survey and laboratory activities were conducted in accordance with ORISE health and safety and radiation protection procedures.

Pre-survey activities included the evaluation and identification of potential health and safety issues. Survey work was performed per the ORISE generic health and safety plans and a site-specific integrated safety management (ISM) pre-job hazard checklist. ITL also provided site-specific safety awareness training.

\section{Calibration AND Quality Assurance}

Calibration of all field and laboratory instrumentation was based on standards/sources, traceable to NIST.

Analytical and field survey activities were conducted in accordance with procedures from the following documents of the Environmental Survey and Site Assessment Program:

- $\quad$ Survey Procedures Manual (May 2008)

- $\quad$ Laboratory Procedures Manual (March 2008)

- Quality Program Manual (November 2007)

The procedures contained in these manuals were developed to meet the requirements of Department of Energy (DOE) Order 414.1C and the U.S. Nuclear Regulatory Commission Quality Assurance Manual for the Office of Nuclear Material Safety and Safeguards and contain measures to assess processes during their performance. 


\section{Calibration Procedures}

Detectors used for assessing surface activity were calibrated in accordance with ISO-7503 ${ }^{1}$ recommendations. Total alpha and total beta efficiencies $\left(\boldsymbol{\varepsilon}_{\text {total }}\right)$ were determined for each instrument/detector combination and consisted of the product of the $2 \pi$ instrument efficiency $\left(\boldsymbol{\varepsilon}_{\mathrm{i}}\right)$ and surface efficiency $\left(\varepsilon_{\mathrm{s}}\right): \varepsilon_{\text {total }}=\varepsilon_{\mathrm{i}} \times \varepsilon_{\mathrm{s}}$.

Th-230 was selected as the alpha calibration source. The $2 \pi$ alpha $\varepsilon_{\mathrm{i}}$ factor for the hand-held gas proportional detector used to collect direct measurements was 0.37 . ISO-7503 recommends an $\varepsilon_{\mathrm{s}}$ of 0.25 for all alpha energies. The total alpha efficiency was 0.09 .

Because of the historical use of multiple beta-emitting radionuclides, the hand-held gas proportional detectors were calibrated with multiple sources representing a broad spectrum of potential contaminants. Ultimately, a Sr/Y-90 efficiency was selected for converting count rate data to $\mathrm{dpm} / 100 \mathrm{~cm}^{2}$ as there was no specific information to determine if a mixture of contaminants existed from which a weighted efficiency could be determined. The $2 \pi$ beta $\varepsilon_{\mathrm{i}}$ factor for the gas proportional detector used to collect direct measurements was 0.61. ISO-7503 recommends an $\varepsilon_{\mathrm{s}}$ of 0.5 for maximum beta energies greater than $0.4 \mathrm{MeV}$ (the maximum beta energy of $\mathrm{Sr} / \mathrm{Y}-90$ is 1.4 MeV). The total beta efficiency was 0.31 .

The decision to use the Sr/Y-90 efficiency was based on the following: Beta efficiencies are energy dependent with efficiency increasing with increasing energy. As a result, using the efficiency for C-14 would provide a more conservative conversion factor. However, when taking the guideline constraints into account for decision making, the assumption that activity is due to $\mathrm{Sr} / \mathrm{Y}-90$ contamination would adequately represent either condition. An example follows. Consider an acquired direct measurement net count rate of $1,000 \mathrm{cpm}$. Converting this count rate to $\mathrm{dpm} / 100 \mathrm{~cm}^{2}$ using the $\mathrm{Sr} / \mathrm{Y}-90$ efficiency results in a reported activity of $2,560 \mathrm{dpm} / 100 \mathrm{~cm}^{2}$; slightly more than 2.5 times the more conservative $1,000 \mathrm{dpm} / 100 \mathrm{~cm}^{2} \mathrm{Sr}-90$ guideline. If the C-14 efficiency of 0.08 were used, the reported activity would be $9920 \mathrm{dpm} / 100 \mathrm{~cm}^{2}$, which is 2 times the C-14 guideline of 5,000 dpm/100 $\mathrm{cm}^{2}$. Based on this, a correct decision can be made for determining compliance regardless of the specific contaminant or mixture of contaminants.

${ }^{1}$ International Standard. ISO 7503-1, Evaluation of Surface Contamination - Part 1: Beta-emitters (maximum beta energy greater than $0.15 \mathrm{MeV}$ ) and alpha-emitters. August 1, 1988. 
Quality control procedures include:

- Daily instrument background and check-source measurements to confirm that equipment operation is within acceptable statistical fluctuations.

- $\quad$ Participation in MAPEP, NRIP, and ITP Laboratory Quality Assurance Programs.

- Training and certification of all individuals performing procedures.

- $\quad$ Periodic internal and external audits

\section{SURVEY Procedures}

\section{$\underline{\text { Surface Scans }}$}

Structural surface scans were performed by passing the detectors slowly over the surface; the distance between the detector and the surface was maintained at a minimum-nominally about $1 \mathrm{~cm}$. Building surfaces were scanned for both alpha or alpha plus beta radiation using either a floor monitor or small area $\left(126 \mathrm{~cm}^{2}\right)$ hand-held gas proportional detectors. Identification of elevated radiation levels was based on increases in the audible signal from the recording and/or indicating instrument.

Beta surface scan minimum detectable concentrations (MDCs) were estimated using the calculational approach described in NUREG-1507. ${ }^{2}$ The scan MDC is a function of many variables, including the background level. Additional parameters selected for the calculation of scan MDCs included a two-second observation interval, a specified level of performance at the first scanning stage of $95 \%$ true positive rate and $25 \%$ false positive rate, which yields a $d$ 'value of 2.32 (NUREG-1507, Table 6.1), and a surveyor efficiency of 0.5. The scanning instrument total efficiency $\left(\boldsymbol{\varepsilon}_{\text {total }}\right)$ for the hand-held gas proportional detectors was approximately 0.31 .

The construction material-specific background levels ranged from 250 to $560 \mathrm{cpm}$ for the gas proportional detectors. To illustrate an example for a hand-held gas proportional detector using a concrete background of $560 \mathrm{cpm}$, the minimum detectable count rate (MDCR) and scan MDC can be calculated using the following relationships:

${ }^{2}$ NUREG-1507. Minimum Detectable Concentrations With Typical Radiation Survey Instruments for Various Contaminants and Field Conditions. US Nuclear Regulatory Commission. Washington, DC; June 1998. 


$$
\begin{gathered}
\mathrm{s}_{\mathrm{i}}=\mathrm{d}^{\prime}\left(\mathrm{b}_{\mathrm{i}}\right)^{1 / 2} ; \\
\mathrm{MDCR}=\mathrm{s}_{\mathrm{i}} \times(60 / \mathrm{i}) ; \text { and } \\
\mathrm{MDCR}_{\text {surveyor }}=\mathrm{MDCR} /(\mathrm{p})^{1 / 2}
\end{gathered}
$$

Where:

$\mathrm{s}_{\mathrm{i}}=$ the minimum detectable number of source counts

$\mathrm{d}^{\prime}=$ the specified level of performance of 2.32

$b_{i}=$ the number of background count in the observation interval

MDCR $=$ minimum detectable count rate

$\mathrm{i}=$ observation interval

$\mathrm{p}=$ surveyor efficiency of 0.5

The equations are combined and the variables are then calculated as follows:

$$
\begin{aligned}
& \mathrm{b}_{\mathrm{i}}=(560 \mathrm{cpm})(2 \mathrm{~s})(1 \mathrm{~min} / 60 \mathrm{~s})=18.7 \text { counts, } \\
& \mathrm{MDCR}=(2.32)(18.7 \text { counts })^{1 / 2}[(60 \mathrm{~s} / \mathrm{min}) /(2 \mathrm{~s})]=198 \mathrm{cpm}, \\
& \mathrm{MDCR}_{\text {surveyor }}=198 /(0.5)^{1 / 2}=279 \mathrm{cpm}
\end{aligned}
$$

The scan MDC is calculated assuming a total efficiency $\left(\boldsymbol{\varepsilon}_{\text {total }}\right)$ of 0.31 :

$$
\text { ScanMDC }=\frac{M D C R_{\text {surveyor }}}{\left(\varepsilon_{\text {total }}\right)} \mathrm{dpm} / 100 \mathrm{~cm}^{2}
$$

For the given background, the estimated scan MDC was $900 \mathrm{dpm} / 100 \mathrm{~cm}^{2}$ for the hand-held gas proportional detector.

Determination of the alpha scan sensitivity is a probability-based determination. That is, at a given scan speed and with the associated low alpha background count rates, what is the probability of the surveyor pausing to investigate. Based on the instrumentation and scan speeds, the alpha scan MDC was approximately $300 \mathrm{dpm} / 100 \mathrm{~cm}^{2}$. 


\section{Surface Activity Measurements}

Measurements of total alpha and total beta surface activity levels were performed using hand-held gas proportional detectors coupled to portable ratemeter-scalers. Count rates (cpm), which were integrated over one minute with the detector held in a static position, were converted to activity levels $\left(\mathrm{dpm} / 100 \mathrm{~cm}^{2}\right)$ by dividing the count rate by the total static efficiency $\left(\varepsilon_{\mathrm{i}} \times \varepsilon_{\mathrm{s}}\right)$ and correcting for the physical area of the detector.

The a priori $\mathrm{MDC}$ for surface activity measurements was calculated using the following equation:

$$
M D C=\frac{3+(4.65 \sqrt{B})}{T x \varepsilon_{T o t} x G}
$$

Where:

$$
\begin{array}{lll}
\mathrm{B} & = & \text { background (total counts) in time interval, } \mathrm{T} \\
\mathrm{T} & = & \text { count time (min) used for field instruments } \\
\varepsilon_{\mathrm{Tot}} & = & \text { total efficiency }=\varepsilon_{\mathrm{i}} \times \varepsilon_{\mathrm{s}} \\
\varepsilon_{\mathrm{i}} & = & \text { instrument efficiency } \\
\varepsilon_{\mathrm{s}} & = & \text { source efficiency } \\
\mathrm{G} & = & \text { geometry (physical detector area } \left.\mathrm{cm}^{2} / 100\right)
\end{array}
$$

The a priori alpha static MDC was approximately $84 \mathrm{dpm} / 100 \mathrm{~cm}^{2}$ using the total efficiency of 0.09 and an instrument background of $2 \mathrm{cpm}$. The physical surface area assessed by the gas proportional detector used was $126 \mathrm{~cm}^{2}$. The a priori beta static MDC was approximately $245 \mathrm{dpm} / 100 \mathrm{~cm}^{2}$ using the total efficiency of 0.31 and the nominal instrument background of $399 \mathrm{cpm}$. The physical surface area assessed by the detector used was $126 \mathrm{~cm}^{2}$.

\section{$\underline{\text { Removable Activity Measurements }}$}

Smear samples for removable gross alpha and gross beta contamination were obtained from each measurement location. Removable activity samples were collected using numbered filter paper disks, $47 \mathrm{~mm}$ in diameter. Moderate pressure was applied to the smear and approximately $100 \mathrm{~cm}^{2}$ of the surface was wiped. Smears were placed in labeled envelopes with the location and other 
pertinent information recorded. Wet smears were used for determining removable H-3 and C-14 activity and the smear placed into a liquid scintillation vial.

\section{RADIOLOGICAL ANALYSIS}

\section{Gross Alpha/Beta}

Smears were counted on a low-background gas proportional system for gross alpha and beta activity. The MDCs of the procedure were $9 \mathrm{dpm} / 100 \mathrm{~cm}^{2}$ and $15 \mathrm{dpm} / 100 \mathrm{~cm}^{2}$ for a 2 -minute count time for gross alpha and gross beta, respectively.

\section{Liquid Scintillation}

Smears were counted for five minutes in a liquid scintillation analyzer for low-energy betas to determine the H-3 and C-14 activity. The typical MDCs of the procedure were $34 \mathrm{dpm} / 100 \mathrm{~cm}^{2}$ and $11 \mathrm{dpm} / 100 \mathrm{~cm}^{2}$ for $\mathrm{H}-3$ and $\mathrm{C}-14$, respectively.

\section{DETECTION LIMITS}

Detection limits, referred to as minimum detectable concentrations, were based on 3 plus 4.65 times the standard deviation of the background count $\left[3+\left(4.65(B K G)^{1 / 2}\right)\right]$. Because of variations in background levels, measurement efficiencies, and contributions from other radionuclides in samples, the detection limits differ from sample to sample and instrument to instrument. 